\title{
Activated tumor cell integrin $\alpha v \beta 3$ cooperates with platelets to promote extravasation and metastasis from the blood stream
}

Martin R. Weber ${ }^{1}$, Masahiko Zuka ${ }^{1}$, Deirdre O’Sullivan ${ }^{1}$, Mario Tschan ${ }^{1}$, Bruce E. Torbett ${ }^{1}$, Andries Zijlstra $^{2}$, James P. Quigley ${ }^{2}$, Karin Staflin ${ }^{1}$, Brian P. Eliceiri ${ }^{3}$, Joseph S. Krueger ${ }^{1}$, Zaverio M. Ruggeri ${ }^{1}$, Brunhilde Felding-Habermann ${ }^{1}$

${ }^{1}$ Department of Molecular and Experimental Medicine, ${ }^{2}$ Department of Cell Biology The Scripps Research Institute, La Jolla, California

${ }^{3}$ Department of Surgery, University of California San Diego, San Diego, CA 92103

Correspondence to B Felding-Habermann, Department of Molecular and Experimental Medicine, MEM 150, The Scripps Research Institute, 10550 North Torrey Pines Road, La Jolla, CA 92037, brunie@scripps.edu

Grant support:

NIH grants CA095458, CA112287, S10RR021060 to BFH, California Breast Cancer Research Grants 12NB-0176, 13NB-0180 to BFH, Mildred Scheel Stiftung fuer Deutsche Krebshilfe Fellowship to MRW, Swedish Research Council Fellowship to KS, Susan G. Komen fellowship PDF0403205 to JSK

Acknowledgments:

We thank Jane Forsyth and Melissa O’Neal for expert technical support.

Running Title:

Integrin activation and platelets support extravasation

Key words:

Integrin activation, metastasis, blood stream, platelets, extravasation 


\begin{abstract}
Metastasis is the main cause of death in cancer patients and understanding mechanisms that control tumor cell dissemination may lead to improved therapy. Tumor cell adhesion receptors contribute to cancer spreading. We noted earlier that tumor cells expressing the adhesion receptor integrin $\alpha \mathrm{v} \beta 3$ can carry the molecule in distinct states of activation, and that cells that metastasize from the blood stream express it in a constitutively high affinity form. Here, we analyzed steps of the metastatic cascade in vivo and asked when and how the affinity state of integrin $\alpha v \beta 3$ confers a critical advantage to disseminating cancer cells. Following tumor cells by real time PCR, non-invasive bioluminescence imaging, intravital microscopy and histology in chick embryos and SCID mice, we identified tumor cell extravasation from the blood stream as a rate-limiting step that is supported by high affinity $\alpha v \beta 3$. We found in vitro and in vivo that successful transendothelial migration depended on cooperation between the tumor cells and platelets involving the high affinity tumor cell integrin and release of platelet granules. Thus, this study identifies activated tumor cell integrin $\alpha v \beta 3$ as critical for early steps of metastasis from the blood stream and highlights the high affinity conformation of the receptor and interaction with platelets as potential targets for prevention of metastatic disease.
\end{abstract}




\section{Introduction}

As cancer progresses, tumor cells disseminate from primary tumors to distant sites via the lymphatics or blood stream. Circulating tumor cells attach to the microvasculature of target organs, penetrate the vessel wall, and survive and proliferate within their new tissue microenvironments. Each step can be rate limiting and involve adhesion receptors such as integrins (1). Integrins are heterodimeric transmembrane receptors that recognize extracellular matrix proteins and may exist in high or low affinity states. The affinity can determine ligand recognition and signals that impact cell survival, adhesion, migration, and invasion (2-7). Integrin affinity is regulated inside the cell and controls the adhesive phenotype and ability to bind soluble ligand (8). Integrin activation to high affinity is especially important for leukocytes and platelets, which circulate within the blood stream and can abruptly change their adhesive properties upon stimulation to interact with the vessel wall at sites of vascular injury or inflammation (911). Integrin activation can further control cell mobilization from bone marrow and other tissues to enter the circulation and relocate to distant tissue niches (12).

We previously showed that human tumor cells can express the adhesion receptor integrin $\alpha v \beta 3$ in distinct states of activation and that tumor cells carrying the high affinity form of the receptor metastasize most efficiently (13). Here, we asked which steps of the metastatic cascade are influenced by integrin activation in tumor cells, and which mechanisms are involved in integrin activationdependent metastasis. We showed earlier by blood perfusion in vitro that expression of $\alpha v \beta 3$ in a high affinity state enables tumor cells to interact with platelets and arrest at components of the vessel wall despite shear forces of blood flow $(13,14)$. Furthermore, we found that activated $\alpha v \beta 3$ helps activate metalloproteinase MMP-9 and supports invasive tumor cell migration (15). In the present study, we followed steps of the metastatic cascade in vivo and examined if, when, and how expression of activated $\alpha v \beta 3$ confers a critical advantage to disseminating tumor cells. We used chick embryos and immune deficient mice to follow tumor cells by real time PCR, non-invasive bioluminescence imaging, intravital microscopy, and histology and analyzed the impact of $\alpha v \beta 3$-activation on primary tumor growth, intravasation, tumor cell dissemination, and target organ colonization. The results indicate that expression of high affinity tumor cell $\alpha \mathrm{v} \beta 3$ is not required for primary tumor growth, but does promote initial steps of target organ colonization from the blood stream to multiple metastatic sites. The mechanism by which activated $\alpha v \beta 3$ supports tumor cell access to target tissues depends on platelets which assist tumor cell extravasation. 


\section{Materials and Methods}

\section{Cell lines, labeling, and in vivo model}

MDA-MB 435 human tumor cells were from Dr. Janet Price (MD Anderson). Variants of the parental cells lacking $\alpha v \beta 3$ and reconstituted with $\alpha v \beta 3 \mathrm{WT}$ or $\alpha \mathrm{v} \beta 3 \mathrm{D} 723 \mathrm{R}$ were previously described (13). Clone E9 cells were isolated by limiting dilution of the parental cells. Parent Combo cells represent a pool of 20 clones, each expressing non-activated $\alpha v \beta 3$ based on in vitro migration and blood perfusion as detailed below.

For in vivo tracking, the tumor cells were stably transduced with red fluorescent protein (dsRed2) or firefly luciferase (Fluc) using a self-inactivating lentiviral vector (16). For hematogenous metastasis, $1 \times 10^{5}-1 \times 10^{6}$ tumor cells were injected into the tail vein of 5- to 8 -week old female C.B17/lcTac-Prkdc scid mice (Taconic) and metastatic activity followed by non-invasive bioluminescence imaging (IVIS200) (17), fluorescence microscopy of lung whole mounts, or real time PCR of human alu sequences in lung extracts using sense primer 5' ACG CCT GTA ATC CCA GCA CTT 3' and antisense primer 5’ TCG CCC AGG CTG GAG TGC A 3’' (18).

\section{Induction of thrombocytopenia}

Thrombocytopenia was induced by i.v. injecting SCID mice with anti-murine GPIb $\alpha$ (CD42b) (Emfret) (3 $\mu \mathrm{g} / \mathrm{g}$ bodyweight).

\section{Flow cytometry}

Integrin expression and $\alpha v \beta 3$ activation were analyzed by flow cytometry (FACS Calibur, Becton Dickinson) with anti $\alpha v \beta 3$ mAb VNR1-27.1 (19), or activation-dependent human ligand-mimetic scFv antibodies Bc-12 and Bc-15 (20). ScFv binding was detected with M2 mouse anti-FLAG and antimouse-APC using TBS with or without $1 \mathrm{mM}$ EDTA, $1 \mathrm{mM} \mathrm{Ca}^{2+}$, or $0.1 \mathrm{mM} \mathrm{Mn}^{2+}$ as binding and washing buffer.

\section{In vitro migration and arrest during blood flow}

Haptotactic migration toward human extracellular matrix proteins was detailed earlier (21).

Cancer cell arrest during blood flow was measured as described (13). Briefly, dsRed tagged tumor cells (red fluorescence) were suspended in human blood anticoagulated with $50 \mathrm{nM}$-Pro-Arg-chloro methyl ketone, spiked with $10 \mu \mathrm{M}$ mepacrine (green fluorescence) and perfused over collagen I or 
subendothelial matrix at a venous wall shear rate of $50 \mathrm{~s}^{-1}\left(4 \mathrm{dynes} / \mathrm{cm}^{2}\right)$. Adhesive events and cell interactions were recorded by fluorescence video microscopy and quantified at 50 predefined positions by image analysis using MetaMorph software.

\section{Dorsal skin fold chamber and intravital microscopy}

Tumor cell interaction with the pulmonary microvasculature was observed by intravital microscopy in lung allografts grown in dorsal skin fold chambers on SCID mice as described (22). Briefly, titanium frames were implanted into a dorsal skin fold, transplanted with SCID lung allografts 3 days later, and allowed to vascularize for 14 days. The allografts were superfused with TNF $\alpha(50 \mu \mathrm{lat} 1 \mu \mathrm{g} / \mathrm{ml}) 2.5$ hours before injecting $2.5 \times 10^{6}$ dsRed tagged tumor cells i.v. together with FITC-dextran (500 kDa) to visualize the vasculature. Adhesive events were observed with an intravital microscope (Leitz Biomed) (22).

\section{Transendothelial migration and platelet preparation}

Human pulmonary microvascular endothelial cells were grown for 5 days on transwell filters $(8 \mu \mathrm{m}$ pores) coated with human fibronectin $(10 \mu \mathrm{g} / \mathrm{ml})$. Monolayer integrity was measured by transendothelial resistance. Conditioned medium from IMR-90 fibroblasts in the lower chamber was used to attract tumor cells $\left(4 \times 10^{4}\right)$ seeded atop the endothelial layer during a $16 \mathrm{hr}$ migration period. Where indicated, washed human platelets $\left(433 \times 10^{3} / \mu 1\right)$ were added to the tumor cell suspension, with or without stimulation with thrombin receptor activating peptide TRAP-6 $(12.5 \mu \mathrm{M})$. Non-migrated tumor cells were removed from the filter tops with cotton swaps, filters fixed in $4 \%$ paraformaldehyde and transmigrated tumor cells counted by fluorescence microscopy on the filter underside in 5 optical fields. 


\section{Results}

Tumor cell model for investigating a role of integrin $\alpha v \beta 3$ activation in hematogenous metastasis

To identify critical steps within the metastatic cascade affected by the activation state of integrin $\alpha v \beta 3$ and to analyze mechanisms involved, we generated a model of tumor cell of variants with a common genetic background and defined levels of $\alpha v \beta 3$ expression and activation. We chose MDA-MB 435 human tumor cells because of their aggressive metastatic behavior in immune deficient mice, which makes them suitable for following individual steps of the metastatic cascade (23). The majority of MDA-MB 435 parental cells expresses integrin $\alpha v \beta 3$, but this population is heterogeneous and contains a subset that expresses $\alpha v \beta 3$ in a constitutively activated functional form, while most cells express the non-activated integrin (13). Our previous results indicate that cells carrying activated $\alpha v \beta 3$ are selected as the metastasis forming cells when the parental cells are injected into the blood stream (13). To generate cells with defined states of $\alpha v \beta 3$ activation without in vivo selection, which may favor additional properties unrelated to $\alpha v \beta 3$, we cloned MDA-MB 435 cells by limiting dilution and analyzed 25 individual clones for $\alpha v \beta 3$ expression and activation state. Clone E9 was identified as carrying $\alpha v \beta 3$ in a constitutively activated form because it bound soluble $\alpha v \beta 3$ ligands including the $\alpha v \beta 3$ specific ligand-mimetic scFv antibody Bc-15. We previously isolated this antibody from a combinatorial immunoglobulin library and showed that it contains an RGD integrin-binding motif typical for $\alpha v \beta 3$ ligands within CDR-H3 (20). Twenty cell clones, each of which expressed $\alpha v \beta 3$ but failed to bind Bc-15 and other soluble $\alpha v \beta 3$ ligands were pooled and named Parent Combo. These cells uniformly express non-activated $\alpha v \beta 3$. Figure 1 summarizes $\alpha v \beta 3$ expression and activation in the used cell variants. Bc-15 binding in the presence of calcium indicates that $\alpha v \beta 3$ is activated. Binding in the presence of manganese indicates that intrinsically non-activated $\alpha v \beta 3$ can be experimentally activated to recognize soluble ligand. Manganese also maximizes intrinsic $\alpha v \beta 3$ activation. Based on these criteria, the cells carrying intrinsically activated $\alpha v \beta 3$ are clone E9, BCM2, and $\beta 3 \mathrm{D} 723 \mathrm{R}$ mutant expressing cells. BCM2 were isolated after exposing very low numbers of MDA-MB 435 parental cells to human blood and recovering surviving, proliferating tumor cells. $\beta 3 \mathrm{D} 723 \mathrm{R}$ cells were generated by reconstituting a $\beta 3$-lacking subpopulation of MDA-MB $435\left(\beta 3^{\text {minus }}\right)$ with the activating $\beta 3$ mutant gene. Reconstitution with the $\beta 3$ wild type gene $(\beta 3 \mathrm{WT})$ results in non-activated $\alpha v \beta 3$ expression $\{7809\}$. 


\section{Functional validation of tumor cell integrin $\alpha v \beta 3$ activation}

Before investigating steps within the metastatic cascade where the activated form of tumor cell integrin $\alpha v \beta 3$ may exert its pro-metastatic properties, we verified the functional activation state of the receptor in our cell model. Cells carrying the activating mutant $\beta 3$ D723R were compared against $\beta 3^{\text {minus }}$ cells, activated clone E9, and non-activated pool Parent Combo. We analyzed two metastasis related tumor cell functions that are mediated by integrin $\alpha v \beta 3$ and which require the activated, high affinity state of the receptor $(15,24)$. One functions is migration toward a fibrinogen substrate, which is exclusively supported by $\alpha v \beta 3$ on these cells (21). The other function is tumor cell attachment to components of the vessel wall during blood flow. This process depends on activated $\alpha v \beta 3$ to bind soluble plasma proteins, such as fibrinogen, and cross link the tumor cells with platelets which then supports the arrest event (14). We found that the $\beta 3$ D723R expressing cells as well as clone E9, but not the $\beta 3^{\text {minus }}$ and Parent Combo cells, migrated actively toward fibrinogen and this was blocked by an inhibitory anti- $\beta 3$

antibody (Fig.2A). Consistent with this finding, $\beta 3$ D723R expressing cells and clone E9, but not $\beta 3^{\text {minus }}$ and Parent Combo cells were able to arrest on a collagen I matrix during blood flow in a plateletdependent manner. The interaction of $\beta 3$ D723R cells and clone E9 with platelets during blood flow and the ability of the tumor cells to arrest were inhibited by a function blocking anti- $\alpha v \beta 3$ antibody (Fig.2B). Cells expressing $\beta 3 \mathrm{WT}$ that failed to bind soluble ligand binding as seen in Fig. 1 also failed to interact with platelets and arrest during blood flow, confirming that $\alpha \mathrm{v} \beta 3$ is not activated (Fig.2B). Thus, our cell model contains variants in which the adhesion receptor integrin $\alpha v \beta 3$ is expressed either constitutively activated ( $\beta 3 \mathrm{D} 723 \mathrm{R}$ cells and clone E9) or not activated (Parent Combo and $\beta 3 \mathrm{WT}$ cells). BCM2 cells behaved like $\beta 3$ D723R cells and clone E9, confirming $\alpha v \beta 3$ activation (not shown).

\section{Activation of tumor cell integrin $\alpha v \beta 3$ promotes initial steps of target organ colonization from the blood stream but does not affect primary tumor growth}

To identify steps within the metastatic cascade in which the activation state of tumor cell integrin $\alpha v \beta 3$ limits success, we first examined the ability of the cells to form a primary tumor. This was done in chick embryos and in the mammary fat pad of SCID mice. The chick model was chosen because it also allows analysis of tumor cell dissociation from a primary tumor and intravasation (18). After inoculating tumor cells $\left(2 \times 10^{6}\right)$ expressing activated mutant receptor $\alpha v \beta 3 D 723 R$ versus cells expressing non-activated 
$\alpha v \beta 3$ WT onto the chorioallantoic membrane (CAM) near the allantoic vein of 10 day old chick embryos, tumors were induced by each cell line and grew at similar rates. They also showed similar rates of intravasation, measured by the number of tumor cells in the lower CAM seven days after implantation (578 $\pm 346 \beta 3 \mathrm{D} 723 \mathrm{R}, 641 \pm 225 \beta 3 \mathrm{WT}, \mathrm{n}=7$ /group). Quantification was based on real time PCR of the human alu sequences as described (18). Similarly, $\beta 3$ D723R expressing cells and those carrying $\beta 3 \mathrm{WT}$, as well as $\beta 3^{\text {minus }}$ cells grew at comparable rates when injected into the mammary fat pad of SCID mice (Fig.3A). Thus, the expression of $\alpha v \beta 3$ and its functional activation state apparently do not limit tumor formation at a primary site or the ability of tumor cells to gain access to the circulation.

We next examined tumor cell colonization of target organs from the blood stream. At this step, expression of constitutively activated $\alpha v \beta 3$ provided the tumor cells with a clear advantage. Following tumor cell arrest and expansion in the lungs of SCID mice after tail vein injection by fluorescence microscopy and alu PCR indicated that cells expressing activated $\alpha v \beta 3 \mathrm{D} 723 \mathrm{R}$ remained in the pulmonary vascular bed and developed metastatic foci more successfully than cells carrying nonactivated $\alpha \mathrm{v} \beta 3 \mathrm{WT}$. Of $1 \times 10^{6}$ injected cells, 8.5-9.5 $\times 10^{5}$ were found in the lungs 3 hours later regardless of $\alpha v \beta 3$ activation. For both cell types, this number dropped sharply within the next 12 hours and reached a low point at 24 hours. At this time and during the following 18 days, $\beta 3$ WTexpressing cells were barely detectable in the lungs while $\beta 3$ D723R carrying cells maintained a level of about $1 \times 10^{5}$ cells at 24 hours and then increased steadily, exceeding $2.5 \times 10^{8}$ cells compared to only $8 \times 10^{5} \beta 3 \mathrm{WT}$ cells on day 35 (Fig.3B). Clearance of tumor cells from lung tissue within the first 24 hours and the early advantage of the $\beta 3 \mathrm{D} 723 \mathrm{R}$ expressing cells were confirmed by fluorescence microscopy monitoring dsRed tagged cells within the lungs (Fig.3C). Intravital microscopy of lung tissue grafts, grown within dorsal skin fold chambers on SCID mice, allowed to detect the arrest process of $\beta 3 \mathrm{D} 723 \mathrm{R}$ expressing cells within the pulmonary microvasculature (Fig. 3D). While the arrest events were rare and not suitable for quantification as only small tissue areas could be observed over time, the captured images provide evidence that activated $\alpha v \beta 3$ expressing cells can successfully arrest within the pulmonary vascular bed. No arrest events were observed after injection of non-activated $\beta 3 \mathrm{WT}$ expressing cells. Together, these results indicate that activated integrin $\alpha v \beta 3$ endows circulating tumor cells with functional properties that enhance the ability of the cells to colonize the lungs from the blood stream. An initial advantage of tumor cells carrying high affinity $\alpha v \beta 3$ translates into enhanced metastatic burden over time. 


\section{Integrin $\alpha v \beta 3$ activation promotes hematogenous metastasis to multiple sites}

We next asked if the advantage conferred to the tumor cells by the high affinity receptor is specific for colonizing the lung, or if $\alpha v \beta 3$ activation more generally promotes metastasis from the blood stream. To address this question, we used variants of our cell model that carry intrinsically activated $\alpha v \beta 3$. It is not known whether tumor cell subpopulations that express the activated integrin in vivo permanently carry the receptor in a high affinity form, or if the activation state is dynamically regulated. Therefore and because of other potential genotypic and phenotypic alterations that might be associated with intrinsic activation of integrin $\alpha v \beta 3$, we compared the metastatic activity of tumor cells with intrinsically activated versus non-activated $\alpha v \beta 3$ and monitored the distribution of metastatic lesions by noninvasive bioluminescence imaging of SCID mice injected with firefly luciferase (F-luc) tagged tumor cells.

E9 cells, cloned in vitro from the parent, express intrinsically activated $\alpha v \beta 3$ (Fig. 1). When injected into the venous circulation, E9 cells actively produced metastatic lesions in the lungs and other target organs of breast cancer and melanoma metastasis. In contrast, Parent Combo cells, representing a pool of 20 clones with non-activated $\alpha v \beta 3$, poorly colonized the lungs and other sites. Figure $4 \mathrm{~A}$ shows typical organ distribution and quantification of metastatic burden in the lungs comparing clone E9 and Parent Combo cells. The differences in lung colonization were statistically significant when measured 14 days after tail vein injection of $1 \times 10^{5}$ tumor cells, as well as 34 days after injecting $1 \times 10^{6}$ tumor cells, to challenge the system. Ex vivo imaging of excised target organs on day 56 revealed increased incidence of metastasis to multiple sites for clone E9 expressing the activated integrin (Fig. 4B). This enhancement of overall metastatic activity and potential to colonize most major target organs of breast cancer and melanoma metastasis from the blood stream, was confirmed with BCM-2 cells, a polyclonal derivative of MDA-MB 435 cells that also expresses intrinsically activated $\alpha v \beta 3$ (Fig. 1). Tail vein injected BCM-2 cells colonized the lungs, brain, liver, adrenal glands and skeletal bone, as seen by noninvasive bioluminescence imaging and histology (Fig. 4B). Similar results were obtained with $\beta 3 \mathrm{D} 723 \mathrm{R}$ cells carrying the experimentally activated mutant receptor. These results indicate that expression of high affinity integrin $\alpha v \beta 3$ provides blood borne tumor cells with a critical advantage during the colonization of major target organs of metastasis. 
Activated tumor cell integrin $\alpha v \beta 3$ cooperates with platelets to promote metastasis from the blood stream

To analyze mechanisms by which the expression of tumor cell integrin $\alpha v \beta 3$ in a high affinity state supports early steps of metastasis from the blood stream, we followed a key function of the activated integrin that initially lead us to appreciate distinct affinity states of $\alpha \mathrm{v} \beta$ in tumor cells, namely the ability of the activated receptor to promote tumor cell interaction with platelets $(13,14)$. Here, we asked if an interaction between tumor cells and platelets could promote not only initial tumor cell arrest within the target organ microvasculature but also subsequent steps of organ colonization. After attaching to the microvascular endothelium of target organs, metastatic tumor cells penetrate the endothelial barrier before invading target tissues. To investigate this step, we analyzed the effect of $\alpha v \beta 3$ activation on tumor cell transendothelial migration in the presence or absence of platelets. Comparing cells expressing experimentally ( $\beta 3 \mathrm{D} 723 \mathrm{R})$ or intrinsically (BCM2) activated $\alpha \mathrm{v} \beta 3$ against cells carrying the nonactivated integrin $(\beta 3 \mathrm{WT})$ revealed that either cell type poorly penetrated monolayers of human pulmonary microvascular endothelial cells in the absence of platelets. However, when platelets were present, tumor cells with activated $\alpha v \beta 3$ transmigrated very efficiently in contrast to cells with the nonactivated integrin. This response was enhanced when platelets were stimulated with thrombin receptor activating peptide (TRAP-6) (Fig.5A). Platelet failed to support tumor cell-transendothelial migration if they had previously released their $\alpha$-granule contents and were washed before addition to tumor cells and endothelial monolayers (Fig.5A). Platelet releasate alone potentiated tumor cell-induced endothelial retraction in 2D cocultures (not shown). This indicates that tumor cell interaction with platelets, and platelet activation resulting in the release of proteins and stimulants contained in platelet granules, strongly promote tumor cell penetration of the lung microvascular endothelium. Importantly, this cooperation with platelets depended on the activated state of tumor cell integrin $\alpha v \beta 3$, as cells expressing the non-activated wild type receptor (Fig.5A) and $\beta 3$ knock-down cells (not shown) largely failed to penetrate the endothelium regardless of the presence of platelets. TRAP-6, used for platelet stimulation, alone had no effect on tumor cell transendothelial migration (Fig.5A).

To examine if the in vitro observed effect of platelets on tumor cell invasion of the lung microvascular endothelium is relevant for hematogenous metastasis in vivo, we rendered SCID mice thrombocytopenic and followed the fate of injected tumor cells within a time window of reduced platelet counts.

Thrombocytopenia was induced by injecting mice with an antibody against murine platelet receptor 
GPIb $\alpha$. This treatment reduced platelet counts 10 -fold from an average of $823 \times 10^{3} / \mu 1$ to $72 \times 10^{3} / \mu 1$ four hours after antibody injection. Counts remained low for 4 days before returning to normal. To examine if platelets support early events of target organ colonization, $5 \times 10^{5}$ tumor cells with activated $\alpha \mathrm{v} \beta 3$, namely $\beta 3$ D723R cells and BCM2, were injected into the venous circulation 4 hours after treatment with anti-platelet antibody when platelet counts reached the low point. Three days later, within the time of reduced platelet counts, the lungs were examined by histology in serial sections throughout the lung tissue. As shown in Table 1, the number of detectable micrometastases for both tumor cell types was reduced in thrombocytopenic mice. Importantly, it was possible to discern extravasated from intravascular tumor cell nests by analyzing the integrity of basement membranes and the endothelium of the pulmonary microvasculature. Tumor cells clearly surrounded by intact endothelium were classified as intravascular. Tumor cells detected in thrombocytopenic animals largely failed to extravasate, while almost all tumor cells in mice with normal platelet counts were found outside the vasculature (Fig.5B). Furthermore, the majority of tumor cells in mice with normal platelet counts began to proliferate and incorporate BrdU on day 3 post injection, while the percentage of BrdU-positive tumor cells was 3.6-3.9 fold reduced in thrombocytopenic animals (Tab.1). Inhibition of tumor cell extravasation by reducing platelet counts early during target organ colonization from the blood stream translated into reduced numbers and sizes of metastatic foci in the lungs 18 days after tumor cell injection (Fig.5C). Considering that platelet counts remained low only during the first 4 days after tumor cell injection, and then returned to normal allowing micrometastases to develop in the presence of normal platelet counts for the following 14 days, the overall reduction in metastatic burden indicates that platelets indeed played a major role during the initial steps of target organ colonization from the blood stream. Thus, an absence of platelets or the inability of tumor cells to cooperate with them can limit metastatic activity. The finding that activation of tumor cell integrin $\alpha v \beta 3$ promotes cooperation with platelets in support tumor cell extravasation as a critical early step of target organ colonization from the blood stream provides a mechanism through which the high affinity form of the integrin promotes metastasis. 


\section{Discussion}

The metastatic cascade comprises discrete steps in each of which tumor cell musts succeed to establish distant lesions (25). Knowledge about mechanisms supporting individual steps of the dissemination process can help define molecular and functional targets for therapeutic intervention and possibly prevention of metastatic disease.

This study has yielded insight into the role of integrin activation in human tumor metastasis and identified extravasation of circulating tumor cells as a step where the affinity state of tumor cell integrin $\alpha v \beta 3$ makes a critical contribution.

The adhesion receptor integrin $\alpha v \beta 3$ allows tumor cells to attach and migrate on extracellular matrix proteins including vitronectin, fibronectin, fibrin, and von Willebrand Factor (26). Ligation of the tumor cell receptor can transduce signals that promote survival, proliferation, and expression of genes supporting invasion, growth factor responses and stromal interaction $(6,27)$. In tumors such as melanoma, glioma, breast and ovarian cancer, $\alpha v \beta 3$ appears in invasive margins and distant lesions, and is associated with malignant progression (26, 28-31). Analyzing metastasis promoting tumor cell functions, we noted earlier that tumor cells can express integrin $\alpha v \beta 3$ in distinct states of activation and that cells from metastatic lesions carry the integrin in a constitutively high affinity form (13). Importantly, targeting of the activated conformer of $\alpha v \beta 3$ on circulating tumor cells with RGD containing ligand mimetic antibodies from cancer patients prevented metastasis from the blood stream (20).

As most prominently shown for platelets and leukocytes, changes in integrin affinity allow the cells to control their adhesive properties within the blood stream and during transit between the circulation and tissues. Prototypic receptors capable of rapid activational changes are platelet integrin $\alpha \operatorname{IIb} \beta 3$ and leukocyte integrins $\alpha \mathrm{M} \beta 2, \alpha \mathrm{L} \beta 2$, and $\alpha 4 \beta 1(4,8)$. Furthermore, activation of several other $\beta 1$ integrins was noted in different cell types associated with their relocation between tissue niches during development, tissue remodeling, and wound healing (7, 32-34). While external signals, agonist stimulation and binding to multivalent ligands can trigger integrin activation from the outside-in (3), constitutive activation as noted for tumor cell $\alpha v \beta 3$ in our previous studies likely depends primarily on inside-out signals that lead to constraints in the molecular structure of the $\alpha \beta$ heterodimer (2). 
Crystallographic analyses of $\alpha v \beta 3(35,36)$ showed that large-scale reorientations of the subunit ectodomains are linked to conformational changes in transmembrane domains (4). This involves formation of integrin activation complexes with intracellular integrin binding proteins, such as talin and Rap1-GTP-interacting adaptor molecule RIAM, which results in enhanced receptor affinity without altering receptor valency $(8,37)$. Recent evidence further suggests that oxidation of redox sensitive cystein residues in integrins can also trigger conformational changes leading to integrin activation and receptor redox modulation (38). This mechanism could be highly relevant in the dynamic control of integrin affinity within microenvironments of activated leukocytes and, perhaps, metastasizing tumor cells that can alter their metabolic properties and production of reactive oxygen species in response to new tissue environments. Our recent proteomic study of bone and brain metastatic cells indicated organ specific metabolic adaptation of the tumor cells with prominent changes in oxidative pathways and redox potential of the cells (17).

To identify steps within the metastatic cascade that are specifically supported by tumor cell integrin $\alpha v \beta 3$, among the many other integrins and adhesion receptors expressed by disseminating tumor cells, and to pin-point in which mechanisms the activation state of $\alpha v \beta 3$ limits the rate of metastatic progress, we chose a cell model where $\alpha v \beta 3$ was identified as important for metastasis and in which proof-ofprinciple exists for the requirement of $\alpha v \beta 3$ activation for the metastatic phenotype (13). We used the MDA-MB 435 cell system because it exemplifies a heterogeneous tumor cell population in which the majority of the cells express non-activated $\alpha v \beta 3$, while a small subset carries the high-affinity receptor apparently in a constitutively activated format. Our previous results indicate that this subset is likely responsible for metastasis (13). However, in vivo mechanisms providing these cells with a critical advantage during dissemination were unknown. Here we used variants of the MDA-MB 435 model, which share a genetic background and in which the $\alpha v \beta 3$ activation state was either controlled experimentally be introducing a $\beta 3$ mutation that renders the heterodimer consitutively active ( $\beta 3 \mathrm{D} 723 \mathrm{R}$ ) (39), or which were selected in vitro from the parental cell population and validated for a stable functional activation state of the receptor. In each of these variants, the general integrin expression profile, including that of other $\alpha \mathrm{v}$ integrins were unaltered. Thus, this model allowed us to follow the specific contribution of activated $\alpha v \beta 3$ to distinct steps of the metastatic cascade, and to identify tumor cell extravasation from the blood stream as a rate-limiting step which requires the high affinity receptor. We found, in vitro and in vivo, that successful transendothelial migration further 
depended on a cooperation between the tumor cells and platelets and involved the release of platelet granules.

Platelet $\alpha$ granules contain a multitude of adhesive ligands, coagulation proteins, pro and antiangiogenic factors, growth factors, chemokines, cytokines, proteases and bioactive lipid metabolites, many of which directly affect endothelial cells and the integrity of the vascular endothelium. For example, platelet released sphingosine 1-phosphate induces rapid loss of endothelial tight junction proteins ZO-1 and Claudin-18 (40), and lysophosphatidic acid induces vascular permeability (41). Metalloproteinases, and other proteases from platelet $\alpha$ granules, may facilitate extravastation of leukocytes and monocytes, specifically when activated by thrombin within the platelet microenvironment $(42,43)$. Furthermore, junctional adhesion molecules, such as JAM-C and adhesion receptor GPIb $\alpha$ expressed on platelets, can serve as binding partners for leukocyte integrin $\alpha \mathrm{M} \beta 2$ and support monocyte and neutrophil extravasation, as well as recruitment of cytotoxic T cells (44-48). Such mechanisms might also be involved in the ability of platelets to support angiogenesis $(49,50)$.

Our results show that platelets and their released factors can very potently promote tumor cell transendothelial migration, and that platelets are in fact required for extravasation of circulating tumor cells in vivo. This platelet-mediated effect, supporting an initial critical step of target organ colonization by circulating tumor cells, depends on the expression of the activated form of tumor cell integrin $\alpha v \beta 3$ in our model. It is possible that platelets, activated within the local microenvironment of tumor cells that have arrested within the capillary bed of target organs, promote endothelial permeability and allow tumor cells expressing the activated form of integrin $\alpha v \beta 3$ to efficiently use the receptor for penetration of the vessel wall and infiltration of target tissues. This potential mechanism is supported by our previous finding that functional activation of $\alpha v \beta 3$ enhances tumor cell migration and promotes activation of metalloproteinases, such as MMP-9 (21). In addition, our in vitro perfusion studies indicated that platelets may also critically contribute to tumor cell arrest during blood flow through an interaction mediated by activated tumor cell integrin $\alpha v \beta 3$. In its high affinity form, $\alpha v \beta 3$ is capable of binding soluble ligands, such as fibrinogen, that can crosslink tumor cells to platelet integrin $\alpha \operatorname{IIb} \beta 3$ (13, 14). This interaction, resulting in platelet supported tumor cell arrest in the microvasculature, resembles platelet-platelet cohesion during thrombus formation and platelet-leukocyte interaction via platelet receptors and activated leukocyte integrin $\alpha \mathrm{M} \beta 2$ in inflammation. It is conceivable that platelet supported tumor cell arrest could promote tumor cell interaction with the endothelium in a variety of 
capillary beds, potentially with or without help from potential target organ specific endothelial receptors, and assist tumor cells in colonizing multiple tissues in which the tumor cells can thrive. Indeed, our data indicate that tumor cells expressing the activated form of integrin $\alpha v \beta 3$ and therefore capable of interacting with platelets, show enhanced metastatic activity in all major target organs examined, and that reduction in platelet numbers lead to a general decrease in metastatic activity from the blood stream. This involves specific adhesive interactions and is not due to unpecific blockage of microvessels by platelet-tumor cell heteroaggregates, because we found no evidence for tumor cell induced thrombus formation in platelet aggregation studies, or thromboembolism by intravital microscopy and histology.

Considering that experimentally induced thrombocytopenia during the initial four days after tumor cell injection strongly inhibited tumor cell extravasation in the mouse model, and with it significantly reduced metastatic burden in the long run, indicates that platelets play a critical role in early steps of the metastatic cascade when tumor cell disseminate via the blood stream. The cooperation between tumor cells and platelets gives tumor cells carrying the activated form of integrin $\alpha v \beta 3$ direct, and possibly indirect advantages for target organ colonization. Together, this study identifies the activated form of tumor cell integrin $\alpha v \beta 3$ as critical for early steps of metastasis from the blood stream and highlights the high affinity conformation of the receptor as a potential therapeutic target for prevention of metastatic disease. 


\section{Figure Legends}

\section{Figure 1.}

\section{Tumor cell model for integrin $\alpha v \beta 3$ activation in tumor metastasis}

Flow cytometry analysis of tumor cell variants expressing defined levels and activation states of integrin $\alpha v \beta 3$. The cell variants were selected from MDA-MB parental cells in vitro or generated by experimental expression of $\beta 3$ subunit gene variants. Left panels: integrin $\alpha v \beta 3$ heterodimer expression (Mab VNR1). Right panels: integrin $\alpha \mathrm{v} \beta 3$ activation state measured by binding of soluble ligand mimetic scFv antibody Bc-15. This human scFv antibody carries an RGD sequence within CDR-H3 and behaves like a natural ligand of the receptor but has the specificity of an antibody and recognizes $\alpha v \beta 3$ only. Lack of scFv binding in the absence of divalent cations (blue lines = no cations) indicates cation dependence. Intrinsic activation of integrin $\alpha v \beta 3$ allows scFv binding in the presence of calcium $(1 \mathrm{mM})($ red line $=\mathrm{Ca})$, while low or no binding in calcium indicates non-activated $\alpha v \beta 3$ in cells that express the receptor. ScFv binding in the presence manganese $(50 \mu \mathrm{M})$ (green line $=\mathrm{Mn})$ is maximized, regardless of the intrinsic $\alpha v \beta 3$ activation state, as long as the cells are $\alpha v \beta 3$ positive. Bold red $+/-$ signs on the right indicate the $\alpha v \beta 3$ activation state.

BCM2 cells were isolated by exposing low cell numbers of the parental cell population to human blood and selecting surviving, proliferating tumor cells. These cells express intrinsically activated $\alpha v \beta 3$.

Parent Combo cells (PaCo) were selected from the parental cell population by single cell cloning and combining 20 clones each of which express non-activated $\alpha v \beta 3$ based on a panel of functional assays, including haptotactic cell migration and blood perfusion as detailed in Figure 2. E9 cells represent a single clone isolated by limiting dilution, expressing intrinsically activate $\alpha v \beta 3 . \beta 3{ }^{\text {minus }}$ cells largely lack $\alpha v \beta 3$ expression and were selected by exposing the parental cell population to anti- $\beta 3$ antibody coupled to saporin to kill $\beta 3$ - positive cells. $\beta 3 \mathbf{W T}$ cells are $\beta 3^{\text {minus }}$ cells transfected with the $\beta 3$ wild type subunit gene resulting in the expression of non-activated $\alpha v \beta 3$. $\beta 3$ D723R cells are $\beta 3^{\text {minus }}$ cells transfected with the $\beta 3$ D723R mutant subunit gene, resulting in the expression of intrinsically activated $\alpha v \beta 3$.

\section{Figure 2.}

\section{Functional validation of tumor cell integrin $\alpha v \beta 3$ activation}

A, Haptotactic migration toward immobilized fibrinogen requires expression of integrin $\alpha v \beta 3$ in an activated functional state. MDA-MB 435 cells selected for lack of $\beta 3$ expression ( $\beta 3$ minus) failed to 
migrate in contrast to their counterparts reconstituted with the constitutively activating $\beta 3$ mutant D723R $(p<0.002)$. Migration of $\beta 3$ mutant D723R expressing cells is strongly inhibited by blocking anti- $\beta 3$ antibody (mab M21-3 at $50 \mu \mathrm{g} / \mathrm{ml})(\mathrm{p}<0.002)$. E9 cells, a single clone isolated from parental MDA-MB 435 cells by limiting dilution, express the same amount of $\alpha v \beta 3$ as Parent Combo cells, a pool of 20 clones expressing the non-activated integrin, but in contrast to Parent Combo cells, E9 cells express $\alpha v \beta 3$ in an intrinsically activated form and migrated actively toward fibrinogen $(\mathrm{p}<0.001)(16 \mathrm{hr}$ migration at $37 \mathrm{C}$ toward human fibrinogen immobilized at the underside of transwell insert filters with 8 $\mu \mathrm{m}$ pores).

B, Left Panel: The ability of tumor cells to attach during blood flow to matrix components of the vessel wall depends upon and indicates the activated state of tumor cell integrin $\alpha v \beta 3$. MDA-MB $435 \beta 3$ minus, $\beta 3$ D723R, E9, and Parent Combo cells were suspended in whole human blood and perfused over a collagen I matrix at a venous wall shear rate of 2 dynes $/ \mathrm{cm}^{2}$ in a parallel plate flow chamber. Tumor cells expressing activated $\alpha v \beta 3$ use the receptor to interact with platelets and, as a result, arrest at the matrix in the presence of shear generated by blood flow. Middle Panel: In $\beta 3$ D723R expressing cells and clone E9, the ability to arrest during blood flow is mediated by $\alpha v \beta 3$, as this function is blocked by anti $\alpha v \beta 3$ antibody (mab VNR1-27.1 at $50 \mu \mathrm{g} / \mathrm{ml}$ ). Right Panel: Typical images, captured at predefined positions, during flow of blood containing either MDA-MB 435 33D723R (left) or $\beta 3 \mathrm{WT}$ (right) expressing cells. The top images, acquired with filter settings for green fluorescence (top images) show arrested blood cells and thrombus forming platelets. The bottom images were captured at the same positions as their corresponding top images but with filters detecting red fluorescence identify the arrested tumor cells. Arrested tumor cells were quantified at 50 predefined positions during ongoing perfusion after same number of tumor cells for each cell type were allowed to pass through the chamber. Statistical significance was assessed by paired, one-tailed $t$-tests.

\section{Figure 3.}

Activation of tumor cell integrin $\alpha v \beta 3$ promotes initial steps of target organ colonization from the blood stream but is not required for primary tumor growth

A, Tumor cell growth within the mammary fat pad as a primary site does not depend on integrin $\alpha v \beta 3$ expression or the activation state of the receptor. MDA-MB 435 cells selected for lack of $\beta 3$ expression $\left(\beta 3^{-}\right)$, reconstituted with $\beta 3$ wild type $(\beta 3 \mathrm{WT})$, or with the constitutively activating mutant $\beta 3$ $(\beta 3 \mathrm{D} 723 \mathrm{R})$ grew at similar rates after injecting $1 \times 10^{6}$ cells into the mammary fat pad of SCID mice 
$(n=8)$. Tumor sizes were measured with calipers by the longest and shortest diameter and calculating the volume as $\left(\mathrm{a}^{2} \mathrm{xb}\right) / 2$.

B, Quantification of tumor cells in SCID mouse lungs at varying time points after tail vein injection of $1 \times 10^{6}$ dsRed tagged MDA-MB 435 cells expressing either constitutively activated $\alpha v \beta 3 D 723 R$ or nonactivated $\alpha v \beta 3 \mathrm{WT}$. Tumor cells were quantified at the indicted time points by real time PCR of human alu sequences within the lung tissue. The initial signal at $3 \mathrm{~h}$ post injection was nearly identical for both cell types and reflects tumor cells within the pulmonary microcirculation, most of which are cleared during the first day. Bars indicate numbers of lung associated tumor cells ( $\mathrm{n}=5$ mice), shown as percent $( \pm$ SEM) of the initial tumor cell number at $3 \mathrm{~h}$ post injection. Cell numbers are based on PCR standard curves, obtained from lung homogenates spiked with known tumor cell numbers.

C, Lung whole mounts 3 to 12 hrs after tail vein injection of dsRed tagged tumor cells as in B, visualizing the tumor cells by fluorescence microscopy (10x). Representative fields are shown.

D, Arrest of $\beta 3$ D723R expressing cells within the pulmonary microvasculature observed by intravital microscopy. Lung allografts were grown in dorsal skin fold chambers on SCID mice, allowed to vascularize for 14 days before superfusion with $\mathrm{TNF} \alpha(50 \mu \mathrm{l}$ at $1 \mu \mathrm{g} / \mathrm{ml}) 2.5$ hours prior to i.v. injection of $2.5 \times 10^{6}$ dsRed tagged tumor cells together with FITC-dextran $(500 \mathrm{kDa})$ to visualize the vasculature. Circulation and adhesive events were recorded by intravital video microscopy (Leitz Biomed). Bar, 50 $\mu \mathrm{m}$.

\section{Figure 4.}

\section{Integrin $\alpha v \beta 3$ activation promotes hematogenous metastasis to multiple target organs}

A. Left panels: Metastatic activity of MDA-MB 435 clone E9 expressing intrinsically activated integrin $\alpha v \beta 3$ compared to 20-clone pool Parent Combo expressing non-activated $\alpha v \beta 3$. Non-invasive bioluminescence imaging of SCID mice 14 days after tail vein injection of $1 \times 10^{5} \mathrm{~F}$-luc tagged tumor cells. Right panels: Quantification of metastatic burden in the lung region by non-invasive bioluminescence imaging 14 days after injecting $1 \times 10^{5}$ tumor cells (Top), or by real time PCR 34 days after injecting $1 \times 10^{6}$ tumor cells to challenge the system and following the tumor cells by human alu sequences (Bottom ). Each data point in the top panel represents signal from one mouse $(n=8)$, the vertical line indicates the median signal in each group. Bars in the lower panel show average values $(+/-$ STDEV) for each group $(n=8)$. Clone E9 caused significantly higher metastatic lung burden than clone pool Parent Combo ( $\mathrm{p}=0.002$ by bioluminescence imaging on day 14 after $1 \times 10^{5}$ injected tumor cells ; 
$\mathrm{p}=0.05$ by alu PCR 34 days after $1 \times 10^{6}$ injected tumor cells). Statistical significance was assessed by paired, one-tailed $t$-tests.

B. Comparison of target organ colonization by tumor cells expressing activated versus non-activated $\alpha v \beta 3$. Incidence of tumor cell burden in the lungs, brain, liver, adrenal glands and bone (hind legs) 56 days after tail vein injection of $1 \times 10^{5}$ clone E9 versus clone pool Parent Combo. Organ associated metastatic burden was detected in excised organs by ex vivo bioluminescence imaging, $n=8$ mice per group. The presence of metastatic lesions was verified by histology (right panels). Brain lesion H\&E staining, Bar $80 \mu \mathrm{m}$. Liver lesion, top panel identifies tumor lesions by immunohistochemistry with anti human CD44 (Mab 29.7) (dark blue), bottom panel shows a neighboring section stained with H\&E and lesions marked with blue asterisks, Bar $200 \mu \mathrm{m}$. Adrenal gland section shown by H\&E staining, lesions marked with blue asterisks, Bar $150 \mu \mathrm{m}$. Mouse images: Multiple target organ colonization validated with polyclonal cell population BCM2 which express activated integrin $\alpha v \beta 3$. Non-invasive bioluminescence imaging of metastasis development in distinct target organs 56 days after tail vein injection $2.5 \times 10^{5}$ tumor cells. Three representative mice are shown (ventral and dorsal). Metastatic burden in the lungs, liver, brain, spine, and adrenal gland was confirmed by bioluminescence imaging of the excised organs and by histology as above.

\section{Figure 5.}

\section{Activated integrin $\alpha v \beta 3$ promotes tumor cell cooperation with platelets in support of extavasation and metastasis from the blood stream}

A. Platelets and activated tumor cell integrin $\alpha v \beta 3$ together promote tumor cell transendothelial migration in vitro. In the presence of platelets, MDA-MB 435 cell variants with activated mutant $\alpha v \beta 3 D 723 R$, or expressing intrinsically activated $\alpha v \beta 3$ (BCM2), penetrated monolayers of human lung microvascular endothelial cells more efficiently than tumor cells with non-activated $\alpha \mathrm{v} \beta 3 \mathrm{WT}(\mathrm{p}=0.03)$. Experimental platelet activation with TRAP-6 (thrombin receptor activating peptide-6, a PAR1 agonist) before addition to the tumor cells, slightly enhances the stimulatory effect of platelets on tumor cell transendothelial migration $(\mathrm{p}=0.13$ for $\beta \mathrm{D} 723 \mathrm{R}, \mathrm{p}=0.21$ for $\mathrm{BCM} 2)$. TRAP-6 alone, or exhausted platelets stimulated with TRAP-6, allowed to release their $\alpha$ granules and washed before addition to tumor cells, did not enhance tumor cell transendothelial migration.

B. Experimental thrombocytopenia prevents tumor cell extravasation in vivo and inhibits metastasis. SCID mice were injected with a polyclonal antibody against mouse platelet glycoporotein GPIb $\alpha(3 \mu \mathrm{g} / \mathrm{g}$ 
bodyweight) to induce temporary thrombocytopenia. After $4 \mathrm{hrs}$, platelet count were reduced from an average of $823 \times 10^{3} / \mu 1$ to an average of $72 \times 10^{3} / \mu 1$ and remained low for 4 days before returning to normal. 4 hours after induction of thrombocytopenia, 5x10 33 D723R expressing cells or BCM2, both expressing activated integrin $\alpha v \beta 3$, were injected into the tail vein. Representative microscopic images of lung sections show tumor cells 3 days after injection into mice with normal platelet counts (top) or 10-fold reduced platelet counts (bottom). With normal platelet counts, multiple tumor cell clusters (green arrows) are seen within the lung tissue outside of blood vessels. With reduced platelet counts, few small tumor cell clusters are seen and almost always found inside blood vessels (green arrow). Bars 100 $\mu \mathrm{m}$. Quantification of in vivo tumor cell extravasation on Day 3 is summarized in Table 1.

C. Experimental thrombocytopenia reduces metastasis from the blood stream. SCID mice were injected with anti platelet glycoprotein GPIb $\alpha$ as above or PBS for control $(n=6)$. Four hours later the platelet count had dropped from an average of $775 \times 10^{3} / \mu 1$ to an average of $65 \times 10^{3} / \mu 1$ in the antibody treated mice. At this time point, $1 \times 10^{5}$ sdRed tagged BCM2 tumor cells were injected into the tail vein and lung metastases counted microscopically in whole mounts of each lung lobe 18 days later. Bars denote the number of metastatic foci per lung \pm SEM, counted regardless of size. Images below show dsRed tumor cell lesions in lung whole mounts representative for each experimental group. Mice with normal platelet counts had significantly more metastases $(p<0.05)$ than mice with thrombocytopenia. Generally, lesions in control mice were also considerably larger than lesions in anti-platelet treated mice. Differences in metastatic burden were confirmed by real time PCR of human alu sequences within the lung tissue (not shown). Statistical significance was assessed by paired, one-tailed $t$-tests. 


\section{References}

(1) Hynes RO. The emergence of integrins: a personal and historical perspective. Matrix Biol 2004;23:333-40.

(2) Arnaout MA, Goodman SL, Xiong JP. Structure and mechanics of integrin-based cell adhesion. Curr Opin Cell Biol 2007; 19:495-507.

(3) Ginsberg MH, Partridge A, Shattil SJ. Integrin regulation. Curr Opin Cell Biol 2005;17:509-16.

(4) Luo BH, Carman CV, Springer TA. Structural Basis of Integrin Regulation and Signaling. Annu Rev Immunol 2007;.25:619-47.

(5) Felding-Habermann B. Integrin adhesion receptors in tumor metastasis. Clin Exp Metastasis 2003;20:203-13.

(6) Stupack DG, Cheresh DA. Get a ligand, get a life: integrins, signaling and cell survival. J Cell Sci 2002;115:3729-38.

(7) Lim ST, Mikolon D, Stupack DG, Schlaepfer DD. FERM control of FAK function: implications for cancer therapy. Cell Cycle 2008;7:2306-14.

(8) Banno A, Ginsberg MH. Integrin activation. Biochem Soc Trans 2008;36:229-34.

(9) Zou Z, Chen H, Schmaier AA, Hynes RO, Kahn ML. Structure-function analysis reveals discrete $\beta 3$ integrin inside-out and outside-in signaling pathways in platelets. Blood 2007;.109:3284-90.

(10) Cantor JM, Ginsberg MH, Rose DM. Integrin-associated proteins as potential therapeutic targets. Immunol Rev 2008;223:236-51.:236-51.

(11) Makino A, Shin HY, Komai Y, Fukuda S, Coughlin M, Sugihara-Seki M, et al. Mechanotransduction in leukocyte activation: a review. Biorheology 2007;44:221-49.

(12) Chigaev A, Waller A, Amit O, Sklar LA. Galphas-coupled receptor signaling actively downregulates alpha4beta1-integrin affinity: a possible mechanism for cell de-adhesion. BMC Immunol 2008;9:26.:26.

(13) Felding-Habermann B, O'Toole TE, Smith JW, Fransvea E, Ruggeri ZM, Ginsberg MH, et al. Integrin activation controls metastasis in human breast cancer. Proc Natl Acad Sci U S A 2001;98:1853-8.

(14) Felding-Habermann B, Habermann R, Saldivar E, Ruggeri ZM. Role of beta3 integrins in melanoma cell adhesion to activated platelets under flow. J Biol Chem 1996;271:5892-900.

(15) Nag S. Morphology and molecular properties of cellular components of normal cerebral vessels. Methods Mol Med 2003;89:3-36.

(16) Swan CH, Buhler B, Steinberger P, Tschan MP, Barbas CF, III, Torbett BE. T-cell protection and enrichment through lentiviral CCR5 intrabody gene delivery. Gene Ther 2006;13:1480-92. 
(17) Chen EI, Hewel J, Krueger JS, Weber MR, Tiraby C, Kralli A, et al. Adaptation of energy metabolism in breast cancer brain metastases. Cancer Res 2007;67:1472-86.

(18) Zijlstra A, Mellor R, Panzarella G, Aimes RT, Hooper JD, Marchenko ND, et al. A quantitative analysis of rate-limiting steps in the metastatic cascade using human-specific real-time polymerase chain reaction. Cancer Res 2002;62:7083-92.

(19) Lam SCT, Plow EF, D'Souza SE, Cheresh DA, Frelinger AL, Ginsberg MH. Isolation and characterization of a platelet membrane protein related to the vitronectin receptor. J Biol Chem 1989;264:3742-9.

(20) Felding-Habermann B, Lerner RA, Lillo A, Zhuang S, Weber MR, Arrues S, et al. Combinatorial antibody libraries from cancer patients yield ligand-mimetic Arg-Gly-Aspcontaining immunoglobulins that inhibit breast cancer metastasis. Proc Natl Acad Sci U S A 2004; 101:17210-5.

(21) Rolli M, Fransvea E, Pilch J, Saven A, Felding-Habermann B. Activated integrin alphavbeta3 cooperates with metalloproteinase MMP-9 in regulating migration of metastatic breast cancer cells. Proc Natl Acad Sci U S A 2003;100:9482-7.

(22) Sikora L, Johansson AC, Rao SP, Hughes GK, Broide DH, Sriramarao P. A murine model to study leukocyte rolling and intravascular trafficking in lung microvessels. Am J Pathol 2003;162:2019-28.

(23) Chambers AF. MDA-MB-435 and M14 Cell Lines: Identical but not M14 Melanoma? Cancer Res 2009;69:5292-3.

(24) Pilch J, Habermann R, Felding-Habermann B. Unique ability of integrin alpha(v)beta 3 to support tumor cell arrest under dynamic flow conditions. J Biol Chem 2002;277:21930-8.

(25) Langley RR, Fidler IJ. Tumor cell-organ microenvironment interactions in the pathogenesis of cancer metastasis. Endocr Rev 2007;28:297-321.

(26) Felding-Habermann B, Cheresh DA. Vitronectin and its receptors. Curr Opin Cell Biol 1993;5:864-8.

(27) Alam N, Goel HL, Zarif MJ, Butterfield JE, Perkins HM, Sansoucy BG, et al. The integringrowth factor receptor duet. J Cell Physiol 2007;213:649-53.

(28) Carreiras F, Denoux Y, Staedel C, Lehmann M, Sichel F, Gauduchon P. Expression and localization of alpha $\mathrm{v}$ integrins and their ligand vitronectin in normal ovarian epithelium and in ovarian carcinoma. Gynecol Oncol 1996;62:260-7.

(29) Albelda SM, Mette SA, Elder DE, Stewart R, Damjanovich L, Herlyn M, et al. Integrin distribution in malignant melanoma: association of the beta 3 subunit with tumor progression. Cancer Res 1990;50:6757-64.

(30) Stettner MR, Wang W, Nabors LB, Bharara S, Flynn DC, Grammer JR, et al. Lyn kinase activity is the predominant cellular SRC kinase activity in glioblastoma tumor cells. Cancer Res 2005;65:5535-43. 
(31) Pignatelli M, Cardillo MR, Hanby A, Stamp GW. Integrins and their accessory adhesion molecules in mammary carcinomas: loss of polarization in poorly differentiated tumors. Hum Pathol 1992;23:1159-66.

(32) Evans RD, Perkins VC, Henry A, Stephens PE, Robinson MK, Watt FM. A tumor-associated beta 1 integrin mutation that abrogates epithelial differentiation control. J Cell Biol 2003;160:589-96.

(33) Huveneers S, Truong H, Fassler R, Sonnenberg A, Danen EH. Binding of soluble fibronectin to integrin alpha5 beta1 - link to focal adhesion redistribution and contractile shape. J Cell Sci 2008;121:2452-62.

(34) Goel HL, Moro L, King M, Teider N, Centrella M, McCarthy TL, et al. Beta1 integrins modulate cell adhesion by regulating insulin-like growth factor-II levels in the microenvironment. Cancer Res 2006;66:331-42.

(35) Xiong JP, Stehle T, Diefenbach B, Zhang R, Dunker R, Scott DL, et al. Crystal structure of the extracellular segment of integrin alpha Vbeta3. Science 2001;294:339-45.

(36) Xiong JP, Stehle T, Zhang R, Joachimiak A, Frech M, Goodman SL, et al. Crystal structure of the extracellular segment of integrin alpha Vbeta3 in complex with an Arg-Gly-Asp ligand. Science 2002;296:151-5.

(37) Luo BH, Carman CV, Takagi J, Springer TA. Disrupting integrin transmembrane domain heterodimerization increases ligand binding affinity, not valency or clustering. Proc Natl Acad Sci U S A 2005;102:3679-84.

(38) Essex DW, Li M. Redox modification of platelet glycoproteins. Curr Drug Targets 2006;7:123341.

(39) Hughes PE, Diaz-Gonzalez F, Leong L, Wu C, McDonald JA, Shattil SJ, et al. Breaking the integrin hinge. A defined structural constraint regulates integrin signaling. J Biol Chem 1996;271:6571-4.

(40) Gon Y, Wood MR, Kiosses WB, Jo E, Sanna MG, Chun J, et al. S1P3 receptor-induced reorganization of epithelial tight junctions compromises lung barrier integrity and is potentiated by TNF. Proc Natl Acad Sci U S A 2005;102:9270-5.

(41) Panetti TS. Differential effects of sphingosine 1-phosphate and lysophosphatidic acid on endothelial cells. Biochim Biophys Acta 2002;1582:190-6.

(42) Stern R. Hyaluronidases in cancer biology. Semin Cancer Biol 2008;18:275-80.

(43) Radjabi AR, Sawada K, Jagadeeswaran S, Eichbichler A, Kenny HA, Montag A, et al. Thrombin induces tumor invasion through the induction and association of matrix metalloproteinase- 9 and beta1-integrin on the cell surface. J Biol Chem 2008;283:2822-34.

(44) van Gils JM, Costa Martins PA, Mol A, Hordijk PL, Zwaginga JJ. Transendothelial migration drives dissociation of plateletmonocyte complexes. Thromb Haemost 2008;100:271-9. 
(45) Bradfield PF, Scheiermann C, Nourshargh S, Ody C, Luscinskas FW, Rainger GE, et al. JAM-C regulates unidirectional monocyte transendothelial migration in inflammation. Blood 2007; 110:2545-55.

(46) Chavakis T, Keiper T, Matz-Westphal R, Hersemeyer K, Sachs UJ, Nawroth PP, et al. The junctional adhesion molecule-C promotes neutrophil transendothelial migration in vitro and in vivo. J Biol Chem 2004;279:55602-8.

(47) Iannacone M, Sitia G, Isogawa M, Marchese P, Castro MG, Lowenstein PR, et al. Platelets mediate cytotoxic T lymphocyte-induced liver damage. Nat Med 2005;11:1167-9.

(48) Iannacone M, Sitia G, Isogawa M, Whitmire JK, Marchese P, Chisari FV, et al. Platelets prevent IFN-alpha/beta-induced lethal hemorrhage promoting CTL-dependent clearance of lymphocytic choriomeningitis virus. Proc Natl Acad Sci U S A 2008;105:629-34.

(49) Italiano JE, Jr., Richardson JL, Patel-Hett S, Battinelli E, Zaslavsky A, Short S, et al. Angiogenesis is regulated by a novel mechanism: pro- and antiangiogenic proteins are organized into separate platelet alpha granules and differentially released. Blood 2008;111:1227-33.

(50) Kisucka J, Butterfield CE, Duda DG, Eichenberger SC, Saffaripour S, Ware J, et al. Platelets and platelet adhesion support angiogenesis while preventing excessive hemorrhage. Proc Natl Acad Sci U S A 2006;103:855-60. 
Figure 1

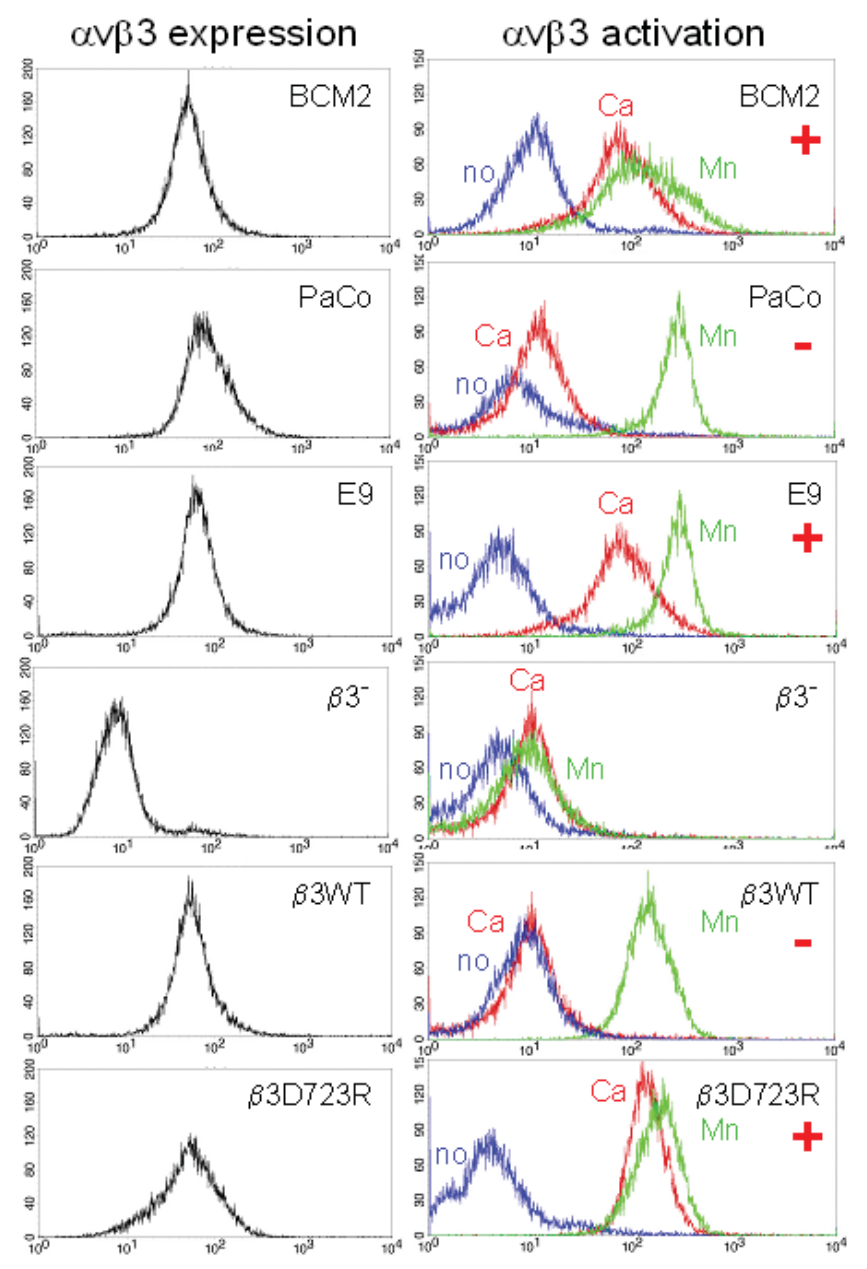




\section{Figure 2}

A avp3 activation dependent migration $B \quad$ Platelet mediated tumor cell arrest during blood flow
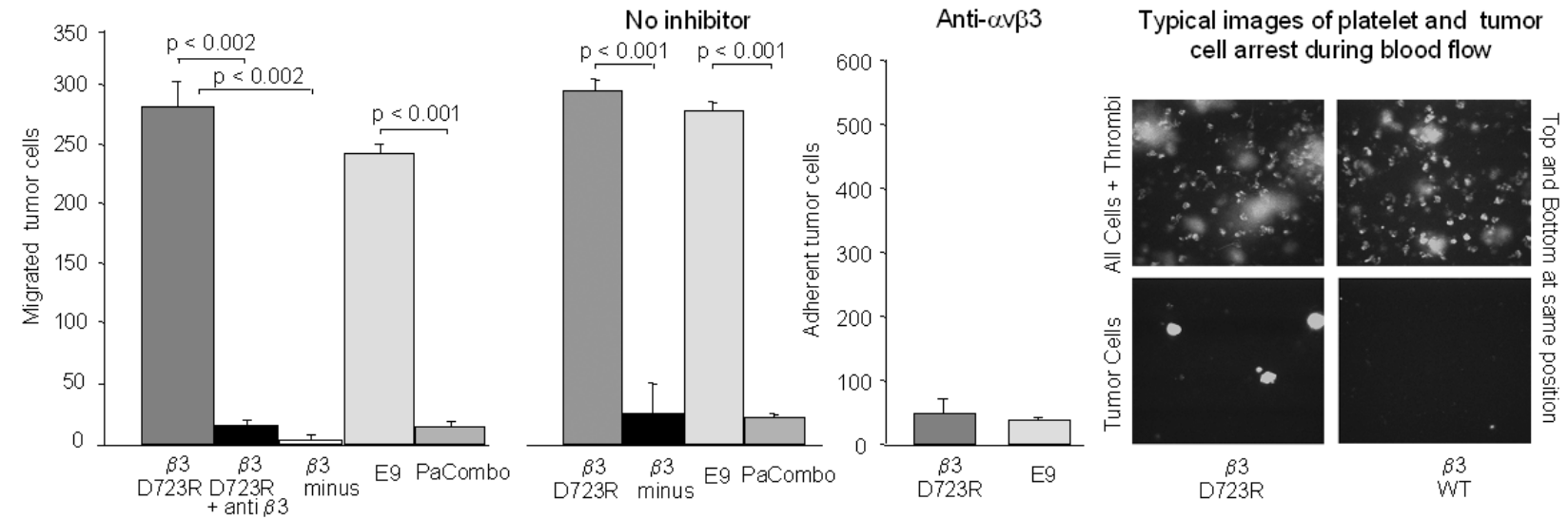
Figure 3
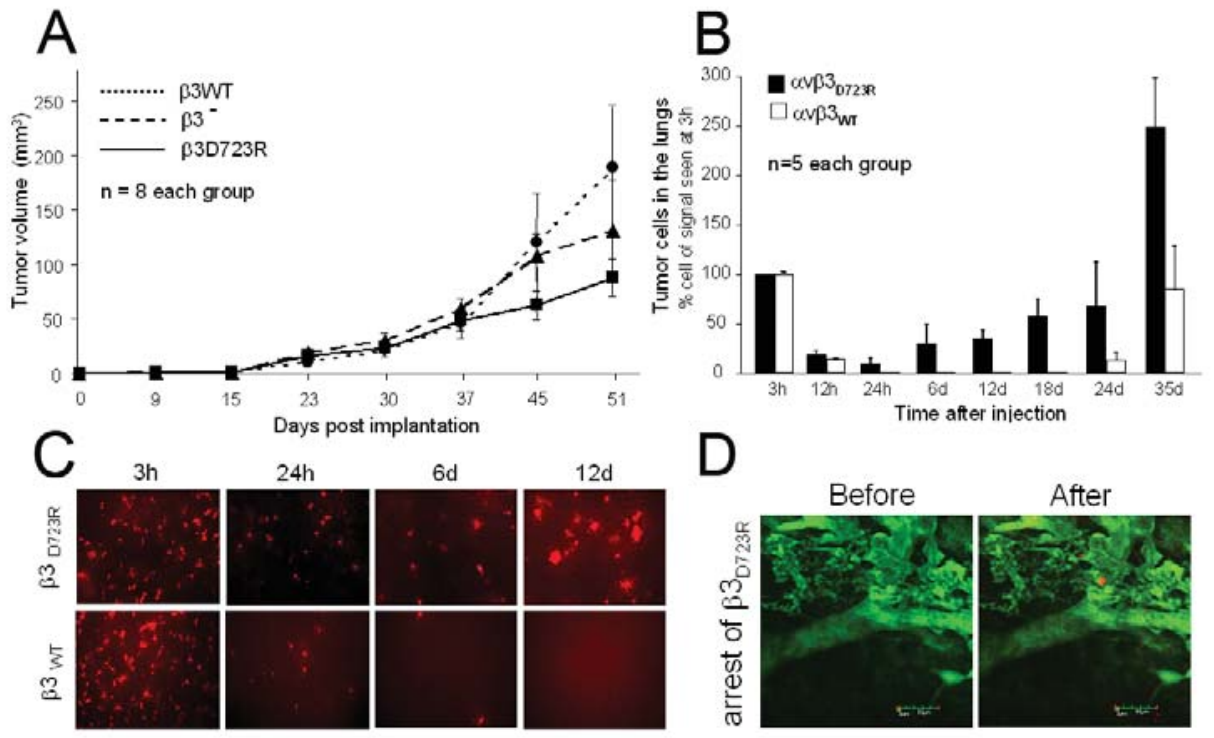


\section{Figure 4}
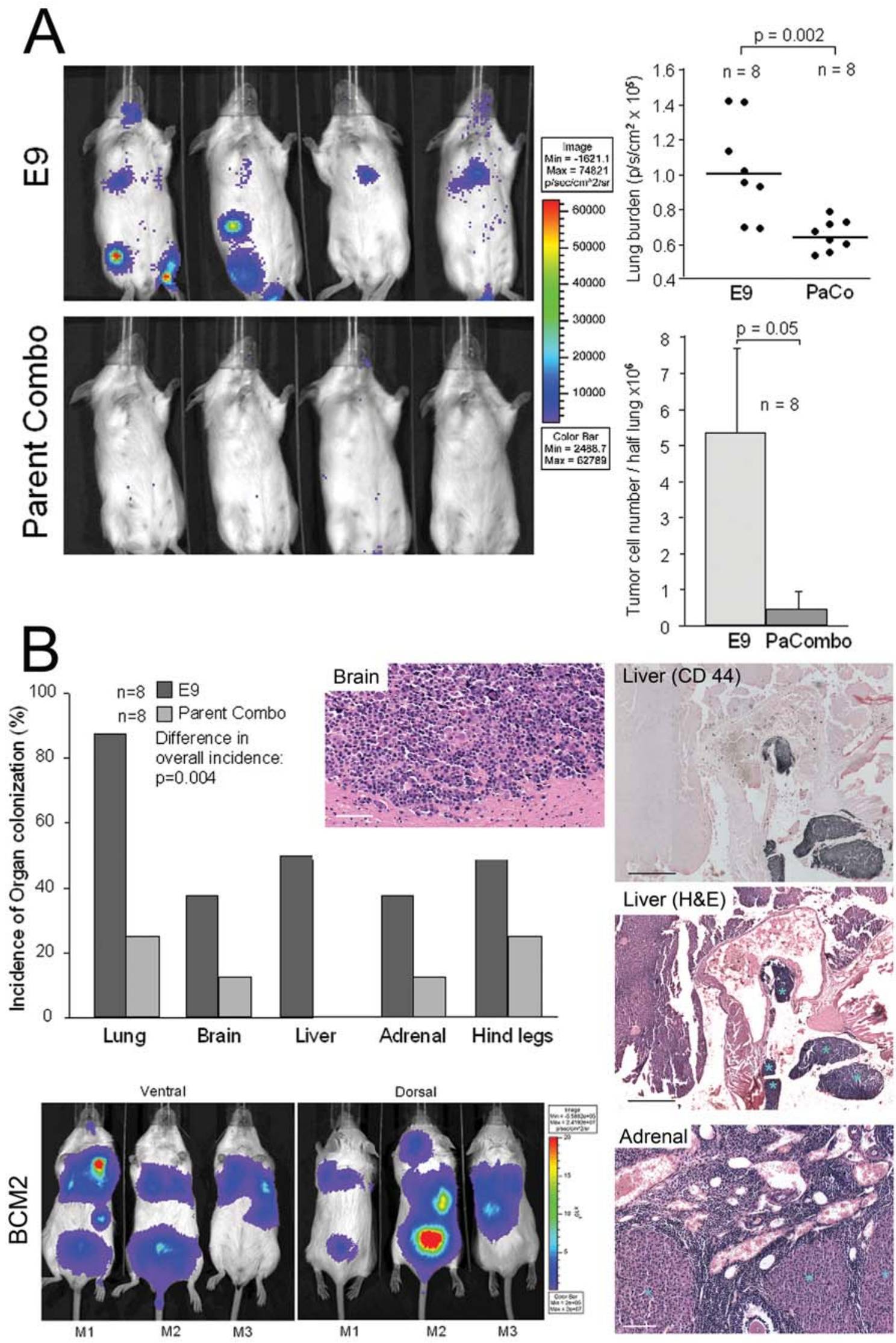


\section{Figure 5}
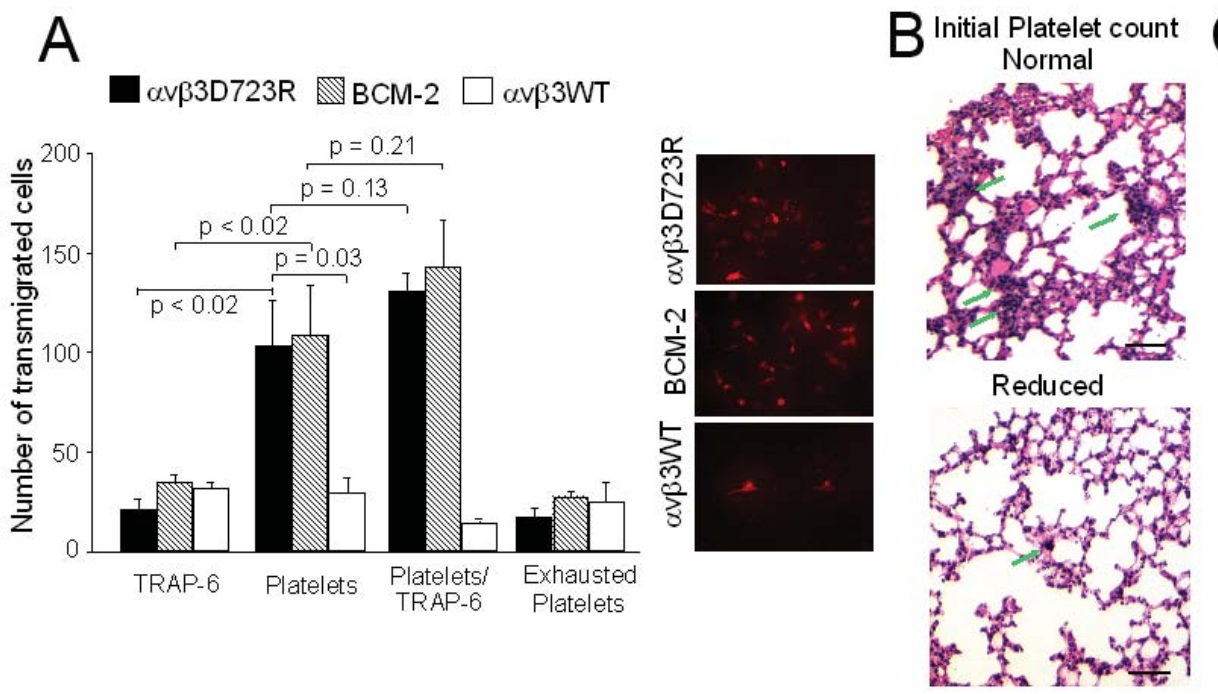

C Initial

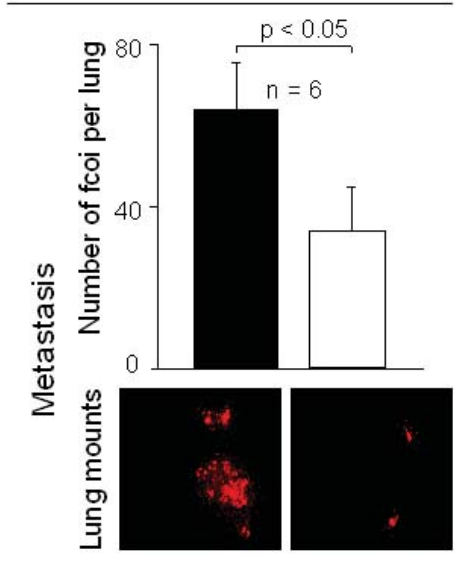




\begin{tabular}{|c|c|c|c|c|c|c|}
\hline $\begin{array}{l}\text { Tumor cell } \\
\text { type }\end{array}$ & $\begin{array}{l}\text { Platelet } \\
\text { count }\end{array}$ & $\begin{array}{c}\text { Measured } \\
\text { lung area } \\
\left(\mathrm{mm}^{2}\right)\end{array}$ & $\begin{array}{c}\text { Number of } \\
\text { metastases in } \\
\text { measured area }\end{array}$ & $\begin{array}{c}\text { Number of } \\
\text { metastases / } \\
\mathrm{mm}^{2}\end{array}$ & $\begin{array}{c}\% \\
\text { extravasated }\end{array}$ & $\begin{array}{l}\% \text { BrdU } \\
\text { positive }\end{array}$ \\
\hline$\beta 3 D 723 R$ & normal & $\begin{array}{r}85.3 \\
140.2 \\
\end{array}$ & $\begin{array}{l}35 \\
83 \\
\end{array}$ & $\begin{array}{l}0.410 \\
0.592 \\
\end{array}$ & $\begin{array}{r}100 \\
95 \\
\end{array}$ & $\begin{array}{l}68.6 \\
62.4 \\
\end{array}$ \\
\hline$\beta 3 D 723 R$ & reduced & $\begin{array}{l}109.6 \\
126.2\end{array}$ & $\begin{array}{r}9 \\
22 \\
\end{array}$ & $\begin{array}{l}0.082 \\
0.174\end{array}$ & $\begin{array}{l}0 \\
0\end{array}$ & $\begin{array}{l}15.5 \\
18.6\end{array}$ \\
\hline BCM2 & normal & $\begin{array}{l}84.4 \\
88.7\end{array}$ & $\begin{array}{l}52 \\
38 \\
\end{array}$ & $\begin{array}{l}0.616 \\
0.428\end{array}$ & $\begin{array}{r}92 \\
100 \\
\end{array}$ & $\begin{array}{l}67.2 \\
63.0\end{array}$ \\
\hline BCM2 & reduced & $\begin{array}{l}84.3 \\
86.7\end{array}$ & $\begin{array}{l}14 \\
18\end{array}$ & $\begin{array}{l}0.166 \\
0.207\end{array}$ & $\begin{array}{l}7 \\
0\end{array}$ & $\begin{array}{l}12.2 \\
14.4\end{array}$ \\
\hline
\end{tabular}

Table 1. Effect of platelets on tumor cell extravasation and early metastasis in vivo.

Morphometric measurements of mouse lung sections 3 days after i.v. injection of MDA-MB 435 ß3D723R or BCM2 cells. Each cell type was injected into mice with normal or 10-fold reduced platelet counts ( $n=2 /$ condition). Data for each mouse indicate the analyzed lung area, numbers of metastases found (lesion count regardless of size), number of metastases/area, percentage of lesions found intravascular (intact vascular endothelium/basement membrane), or near blood vessels with broken vascular basement membrane indicating extravasation. Also included is the percentage of lesions showing BrdU uptake (24 h in vivo pulse) indicating proliferative activity, regardless of lesion size. Tumor cell lesions in mice with normal platelet counts were generally considerably larger and had higher proliferative activity than lesions in thrombocytopenic mice. 